\title{
Histological Diagnosis Determines Complications of Percutaneous Renal Biopsy: A Single-Center Experience in 353 Patients
}

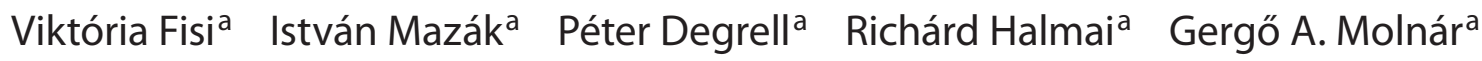 \\ Eszter Fehér $^{b} \quad$ Kinga Németh $^{\mathrm{b}}$ István Pintér ${ }^{c} \quad$ Tibor Kovács $^{\mathrm{a}} \quad$ István Wittmann ${ }^{\mathrm{a}}$ \\ aSecond Department of Medicine and Nephrological Center, and bepartment of Radiology, University of Pécs, \\ Pécs, and ' Outpatient Department, Hospital of Siklós, Siklós, Hungary
}

\section{Key Words}

Renal biopsy $\cdot$ Complications $\cdot$ Histological diagnosis

\begin{abstract}
Background: We studied the connection between complication occurrence related to renal biopsies and histological diagnoses of the biopsy specimen. We also analyzed the distribution of diagnoses in our population. Methods: We retrospectively studied 353 patients undergoing renal biopsy at the same center. Biopsies were performed after marking the site of puncture by ultrasound imaging. Connection of complications with diagnoses and clinical parameters was evaluated. Results: Complication rate was $44.5 \%$ in our study. There was a significantly lower rate of complications in patients with diabetic nephropathy (likelihood ratio, $L R=$ 0.44 ) or acute tubular necrosis ( $L R=0.38$ ), while patients with thin basement membrane syndrome had a more than 6-fold higher risk for development of intrarenal hemorrhage than others. Patients with vasculitis $(L R=2.88)$ and acute interstitial nephritis $(L R=3.18)$ have a more than doubled risk for arteriovenous shunts, while in patients with severe arteriosclerosis the prevalence of this complication was lower ( $L R=$ 0.46). Arteriovenous shunts developed also at a significantly higher rate in patients with rapidly progressive glomerulonephritis. Conclusion: Patients with thin basement mem-
\end{abstract}

brane syndrome, vasculitis, rapidly progressive glomerulonephritis or acute interstitial nephritis should be observed more carefully after renal biopsy due to the significantly higher risk for certain complications.

Copyright $\odot 2011$ S. Karger AG, Basel

\section{Introduction}

Renal biopsy is an essential procedure in establishing the histological diagnosis, adequate therapy, and prognosis of numerous nephrological and systemic diseases [1]. Since it is an invasive method, it has potential complications [2-4]. Complication rate can be diminished by adequate indication of biopsy and appropriate pre-and postbiopsy monitoring and management. The most frequent clinically significant complications following percutaneous renal biopsy include perirenal, intrarenal and retroperitoneal hemorrhages, arteriovenous shunts with or without requirement of selective embolization, infections and very rarely nephrectomy and death.

V.F. and I.M. contributed equally to this work.

\section{KARGER \\ Fax +41613061234 E-Mail karger@karger.ch} www.karger.com

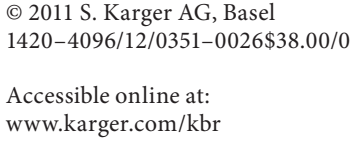

Prof. Dr. István Wittmann

2nd Department of Medicine and Nephrological Center, University of Pécs

Pacsirta str. 1

HU-7624 Pécs (Hungary)

Tel. +36 72536 050, E-Mail istvan.wittmann@ aok.pte.hu 
Recently, the number of articles analyzing the distribution of diagnoses and complications related to percutaneous renal biopsies has increased [5-7]. A few articles also deal with the risk factors of complications, but these papers analyzed mainly the effects of various clinical data but not the impact of histology on the developing bleeding complications $[2,8,9]$. Thus, the relationship between diagnoses and complications is not well analyzed yet. There are some data which show that in the case of autoimmune diseases, the rate of bleeding complications is higher, and there are some conflicting data reported about complications associated with amyloidosis after biopsy $[3,10,11]$, but there is no evidence for the connection of certain diagnoses and different types of complications. The purpose of our study was to examine whether there is a significant relationship between certain histological diagnoses found in the biopsy sample and the type of complication.

\section{Patients and Methods}

We analyzed the frequency and the risk factors for different forms of complications associated with percutaneous renal biopsies on native kidneys performed at the 2nd Department of Medicine and Nephrological Center at the University of Pécs. Association of the developing complications with age, gender, BMI and the histological diagnoses detected in the biopsy samples was also examined. Percutaneous renal biopsies have been performed at our Department for 45 years. Currently, we perform 80-100 kidney biopsies per year.

We retrospectively studied all adult patients $(\mathrm{n}=353)$ undergoing renal biopsy at our Department between 1 January 2006 and 31 December 2009. Patients below the age of 18 and transplant kidney biopsies were excluded from this study. Patients whose biopsies were performed elsewhere but had the histological processing performed at our department and whose biopsy specimen did not contain enough material for histological analysis were also excluded. All biopsies were performed by the same three experienced nephrologists (each of them perform 20-30 biopsies annually) using 14-gauge modified Menghini needles. Biopsies were carried out without real-time ultrasound guidance, after marking the site of puncture by the help of ultrasound imaging which was carried out by the same two radiologists who are experts in renal ultrasonography.

Prior to the biopsy procedure, detailed history taking, physical and laboratory examinations were performed. Pre-biopsy laboratory tests included evaluation of blood count, renal function, coagulation profile and urinalysis. Anatomic abnormalities of the kidneys and exact renal parameters were described by ultrasound examinations before biopsy. Antiaggregation therapy was discontinued 1 week before biopsy. Percutaneous biopsy was contraindicated if platelet count was $<70 \mathrm{~g} / \mathrm{l}$, hemoglobin $<90 \mathrm{~g} / \mathrm{l}$ or prothrombin level was higher than 1.2 INR. The biopsy was also contraindicated in the presence of echogenic small kidneys (kidney length $<8 \mathrm{~cm}$ ), severe uncontrolled hypertension $(>160 / 110 \mathrm{~mm}$ $\mathrm{Hg}$ ), significant hydronephrosis, urinary tract infection (positive urine culture and/or symptoms), multiple bilateral renal cysts or other renal masses and in the case of uncooperative patient.

All specimens were evaluated by the same pathologist using light microscopy, immunofluorescence and electron microscopy in $100 \%$ of cases as recommended in previous guidelines $[12,13]$. Besides evaluating the tubuloglomerular diseases, the state of vessels was also described in all cases using Banff 97 classification of arteriosclerosis and Bader's classification of arteriolosclerosis [14, 15]. The 15 most frequent diagnoses were analyzed in this study. Diagnoses that occurred in less than 10 cases in our population were defined as 'other'. In our Department, a preliminary histological diagnosis can be established within $3 \mathrm{~h}$ after biopsy by performing immunofluorescent evaluation and hematoxylin-eosin staining with periodic acid-Schiff reaction on fresh frozen sections.

After biopsy, patients were closely observed for at least $24 \mathrm{~h}$, as recommended by Whittier and Korbet [16] and Bollée et al. [17]. Patients remained in bed, lying on their backs the whole time with a sandbag under the site of puncture for $4 \mathrm{~h}$. A fluid intake of at least $3 \mathrm{l}$ was recommended for this period. Blood pressure and heart rate were monitored every hour during the first $6 \mathrm{~h}$. In the case of stable parameters, the values were observed every $4 \mathrm{~h}$ following the first $6 \mathrm{~h}$. Control ultrasound and laboratory examinations were carried out $24 \mathrm{~h}$ after biopsy (or earlier in the presence of any complaint) to detect any complication in time. Complications were classified as major and minor complications. Major complications included hemorrhage requiring transfusion, arteriovenous shunt with necessity of selective embolization, infection at the site of puncture, need for nephrectomy, and death. Minor complications were defined as perirenal, intrarenal or retroperitoneal hemorrhage not requiring transfusion and arteriovenous shunt without necessity of embolization. Hemorrhages include all hematomas visible during ultrasound examination, regardless of their size.

Statistical analyses were performed on crosstabs (patients having or not having a certain histological diagnosis vs. patients having or not having a certain complication) using $\chi^{2}$ or Fisher's exact tests as appropriate and stepwise multivariate logistic regression analyses. Calculations were performed using the SPSS Statistics 17.0 program. Data with normal distribution are reported as mean \pm standard deviation, data with not normal distribution are expressed as median (range). p values less than 0.05 were considered statistically significant. Likelihood ratio (LR) below 1 indicates a lower complication occurrence, while LR over 1 means a higher complication rate in the case of the studied diagnosis.

\section{Results}

The mean age of patients at the time of biopsy was 49 \pm 14 years, $58 \%$ of patients were male. The mean BMI was $28 \pm 6$, hemoglobin level before biopsy was $125 \pm$ $26 \mathrm{~g} / \mathrm{l}$, and the median of serum creatinine level was 113 $\mu \mathrm{mol} / \mathrm{l}$ (table 1).

The number of diagnoses per biopsy sample varied between 0 and 5 (fig. 1). The mean number of diagnoses 
detected in one sample was 2, which was present in 158 cases $(44.8 \%)$. One diagnosis occurred in 97 cases $(27.5 \%)$, 3 diagnoses in 73 (20.7\%), 4 diagnoses in $16(4.5 \%)$ and 5 diagnoses in 5 cases (1.4\%). In 4 cases (1.1\%), there was only normal renal tissue present in the biopsy material. No significant connection could be detected between the number of histological diagnoses per biopsy sample and complication rate $(\mathrm{p}=0.90)$.

Analyzing the incidence of various renal diseases diagnosed by biopsy, we found that the most common diagnosis was moderate and severe arterio- and arteriolosclerosis, which was present in 164 cases (46.5\%; table 2). IgA nephropathy and vasculitis were detected in 71 and 69 cases, respectively (20.1 and $19.5 \%$ of samples). Secondary focal segmental glomerulosclerosis, membranous glomerulonephritis and diabetic nephropathy were also frequent in our population $(58,55$ and 39 cases, which means 16.4 , 15.6 and $11 \%$ of biopsies, respectively). Further diagnoses which were present in over 10 cases can be seen in table 2 . Diagnoses which were present in less than 10 cases were defined as 'other'. This includes primary focal segmental glomerulosclerosis, Alports's syndrome, amyloidosis, postinfectious glomerulonephritis, IgM nephropathy, contrast material-induced nephropathy, mesangioproliferative glomerulonephritis, non-diabetic nodular sclerosis, mesangiocapillary glomerulonephritis, immunotac- toid glomerulonephritis, focal segmental glomerulonephritis and lecithin-cholesterol acyltransferase deficiency.

The most frequent clinical presentations which have indicated renal biopsy in our population were nephrotic syndrome, acute kidney injury, proteinuria, microscopic hematuria, proteinuria with hematuria, proteinuria with hematuria and azotemia, and proteinuria together with azotemia (table 3). Nephrotic syndrome had a significant connection with membranous glomerulonephritis, while acute kidney injury was mainly accompanied with rapidly progressive glomerulonephritis (RPGN), vasculitis,

Table 1. Patient characteristics at biopsy

\begin{tabular}{lc}
\hline Age, years & $49 \pm 14$ \\
Male & $206(58 \%)$ \\
BMI & $28 \pm 6$ \\
Creatinine, $\mu \mathrm{mol} / \mathrm{l}$ & $113(41-1,511)$ \\
Hgb, g/l & $125 \pm 26$ \\
Htc, $\%$ & $38.8 \pm 24.4$ \\
Platelet, g/l & $259 \pm 103$
\end{tabular}

Values with a normal distribution are expressed as mean \pm standard deviation, serum creatinine is expressed as median (range).
Fig. 1. Distribution of the number of histological diagnoses per case in 353 percutaneous renal biopsies. There were 4 cases with normal kidney tissue in the sample without any diagnosis. The mean number of histological diagnoses per patient was 2 , which was the case in 158 biopsy samples in our study (for instance diabetic nephropathy associated with membranous glomerulonephritis).

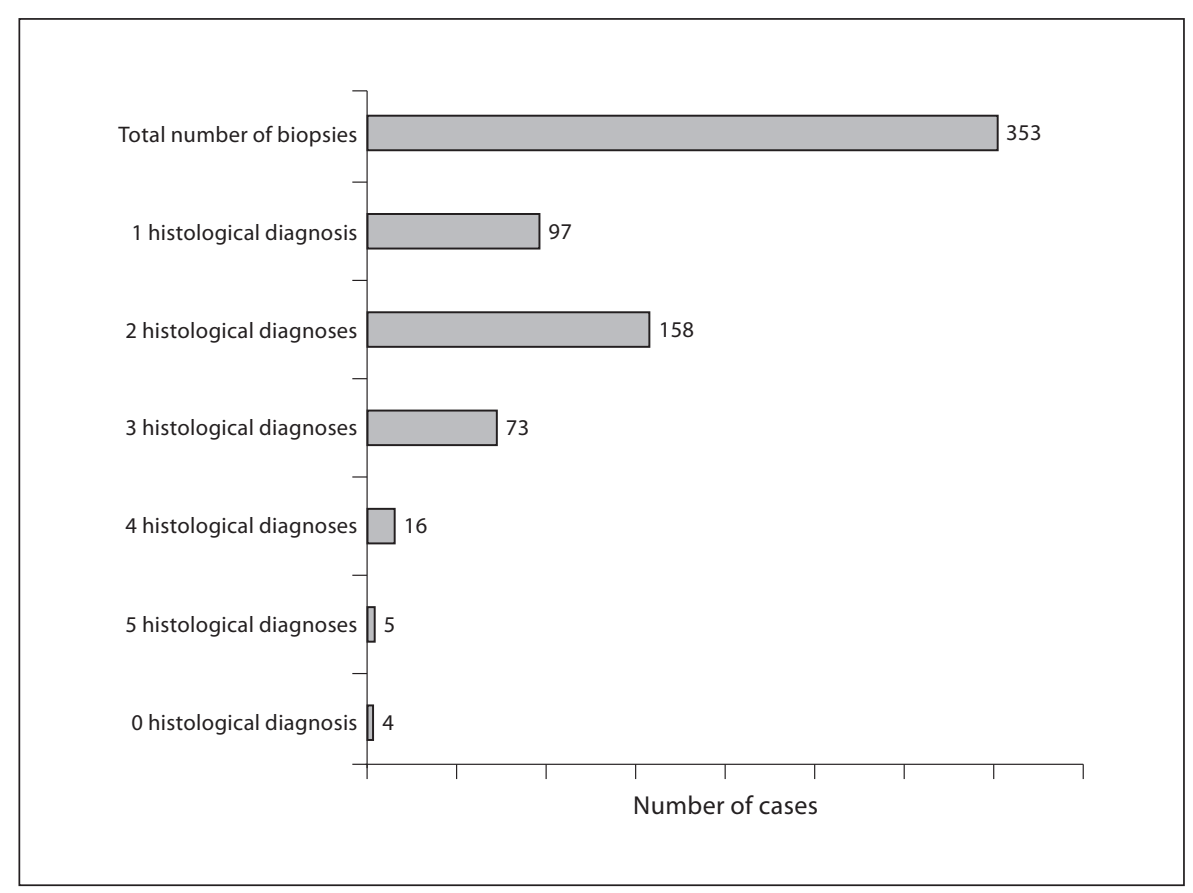


acute interstitial nephritis and acute tubular necrosis. Most patients with isolated microscopic hematuria or hematuria together with proteinuria had thin basement membrane syndrome. Symptoms which were present in less than 10 cases were excluded.

Post-biopsy complications occurred in 157 cases $(44.5 \%)$ in the studied population (fig. 2). The most frequent complication was perirenal hematoma, which developed in 143 cases (40.5\%). This includes all hematomas visible by ultrasound $24 \mathrm{~h}$ after biopsies, with the width of hemorrhage zone starting even from $1 \mathrm{~mm}$. The maximum width of perirenal hemorrhage band was $128 \mathrm{~mm}$ (mean hemorrhage size was $13 \pm 15 \mathrm{~mm}$ ). Intrarenal hematoma was present in 13 patients (3.7\%), while smaller but visible retroperitoneal bleeding developed in 4 cases (1.1\%). In 12 of these patients (3.39\% of all cases and $8.11 \%$ of overall bleedings), hematomas were visible in two locations, either perirenal hematoma together with intrarenal hemorrhage or perirenal hematoma together with retroperitoneal bleeding. In 26 patients (7.4\%), arteriovenous shunts developed and closed spontaneously, while in 6 cases $(1.7 \%)$ embolization was required to treat this complication. In our study, nephrectomy was necessary in 2
Table 2. Frequency of renal diseases in 353 renal biopsies

\begin{tabular}{lrc}
\hline & Cases & $\begin{array}{c}\text { Percent of } \\
\text { all biopsies }\end{array}$ \\
\hline Moderate/severe arteriosclerosis & 164 & 46.5 \\
IgA nephropathy & 71 & 20.1 \\
Vasculitis & 69 & 19.5 \\
Secondary FSGS & 58 & 16.4 \\
Membranous GN & 55 & 15.6 \\
Diabetic nephropathy & 39 & 11.0 \\
Thin basement membrane syndrome & 34 & 9.6 \\
Mild arteriosclerosis & 29 & 8.2 \\
Rapidly progressive GN & 27 & 7.6 \\
Acute interstitial nephritis & 27 & 7.6 \\
Minimal change disease & 24 & 6.8 \\
Acute tubular necrosis & 16 & 4.5 \\
Lupus nephritis & 15 & 4.2 \\
Cast nephropathy & 14 & 4.0 \\
Nephrosclerosis & 14 & 4.0 \\
Other & 65 & 18.4 \\
\hline
\end{tabular}

Diagnoses that occurred in less than 10 cases in our study were defined as 'other'.

FSGS = Focal segmental glomerulosclerosis; GN = glomerulonephritis.

Table 3. Relationship between histological diagnoses and clinical presentations

\begin{tabular}{|c|c|c|c|c|c|c|c|}
\hline & $\begin{array}{l}\text { Nephrotic } \\
\text { syndrome }\end{array}$ & AKI & PU & $\begin{array}{l}\text { Microscopic } \\
\text { HU }\end{array}$ & PU with HU & $\begin{array}{l}\text { PU with HU } \\
\text { and azotemia }\end{array}$ & $\begin{array}{l}\text { PU with } \\
\text { azotemia }\end{array}$ \\
\hline ATN & $1(8)$ & $9(69)^{*}$ & $0(0)$ & $0(0)$ & $0(0)$ & $1(8)$ & $2(15)$ \\
\hline Secondary FSGS & $20(36)$ & $1(2)$ & $6(11)$ & $3(5)$ & $13(23)$ & $8(14)$ & $5(9)$ \\
\hline DNP & $11(29)$ & $1(2)$ & $6(16)$ & $3(8)$ & $6(16)$ & $5(13)$ & $6(16)$ \\
\hline MCD & $8(36)$ & $0(0)$ & $6(28)^{*}$ & $0(0)$ & $5(23)$ & $2(9)$ & $1(4)$ \\
\hline TBM syndrome & $4(13)$ & $1(4)$ & $2(6)$ & $9(29)^{*}$ & $13(42)^{*}$ & $2(6)$ & $0(0)$ \\
\hline Vasculitis & $6(9)$ & $21(32)^{*}$ & $1(2)$ & $3(5)$ & $10(15)$ & $20(31)^{*}$ & $4(6)$ \\
\hline IgA NP & $6(9)$ & $1(2)$ & $7(10)$ & $3(4)$ & $28(41)^{*}$ & $19(28)^{*}$ & $4(6)$ \\
\hline MGN & $40(73)^{*}$ & $0(0)$ & $6(11)$ & $0(0)$ & $8(14)$ & $0(0)$ & $1(2)$ \\
\hline Mild AS & $11(41)$ & $1(4)$ & $3(12)$ & $1(4)$ & $8(31)$ & $2(8)$ & $0(0)$ \\
\hline Moderate/severe AS & $43(28)$ & $18(12)$ & $18(12)$ & $5(3)$ & $29(18)$ & $30(19)$ & $13(8)$ \\
\hline Nephrosclerosis & $2(16)$ & $0(0)$ & $0(0)$ & $0(0)$ & $1(8)$ & $5(38)$ & $5(38)^{*}$ \\
\hline AIN & $1(4)$ & $14(56)^{*}$ & $1(4)$ & $0(0)$ & $1(4)$ & $5(20)$ & $3(12)$ \\
\hline RPGN & $1(4)$ & $13(50)^{*}$ & $0(0)$ & $1(4)$ & $1(4)$ & $10(38)^{*}$ & $0(0)$ \\
\hline Lupus nephritis & $1(7)$ & $0(0)$ & $2(13)$ & $0(0)$ & $6(40)$ & $6(40)^{*}$ & $0(0)$ \\
\hline Cast NP & $2(14)$ & $4(29)$ & $1(7)$ & $1(7)$ & $1(7)$ & $2(14)$ & $3(22)$ \\
\hline Other & $23(39)$ & $8(14)$ & $2(3)$ & $3(5)$ & $11(19)$ & $8(13)$ & $4(7)$ \\
\hline
\end{tabular}

$\mathrm{AKI}=$ Acute kidney injury; $\mathrm{PU}=$ proteinuria; $\mathrm{HU}=$ hematuria; $\mathrm{ATN}=$ acute tubular necrosis; $\mathrm{DNP}=$ diabetic nephropathy; $\mathrm{MCD}=$ minimal change disease; $\mathrm{TBM}=$ thin basement membrane; $\mathrm{NP}=$ nephropathy; $\mathrm{MGN}=$ membranous glomerulonephritis; $\mathrm{AS}=$ arterio- and arteriolosclerosis; AIN = acute interstitial nephritis; RPGN = rapidly progressive glomerulonephritis .

${ }^{*} \mathrm{p}<0.05$, significant association between presence of a histological disease and clinical syndrome using $\chi^{2}$ or Fisher's exact test, as appropriate. Figures in parentheses are percentages. 
Fig. 2. Distribution of complications related to percutaneous renal biopsies in 353 cases. Two complications occurred in the same patient in 25 cases, while one complication was present in 147 patients. The number of hematomas means all hematomas visible during post-biopsy ultrasound examinations (size varied between 1 and $128 \mathrm{~mm})$.

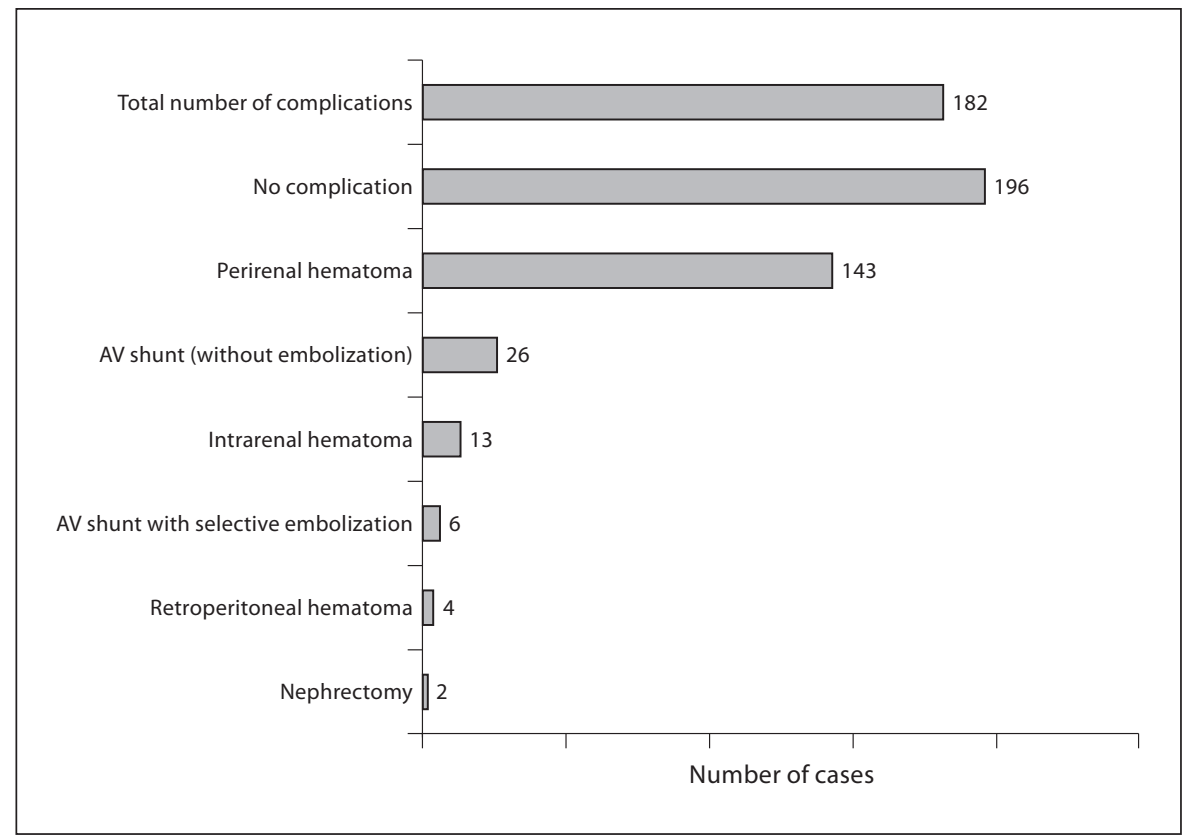

Table 4. Percentage of complications according to the histological diagnoses

\begin{tabular}{lcc}
\hline & $\begin{array}{c}\text { Patients with } \\
\text { complication }\end{array}$ & $\mathrm{p}$ \\
\hline Thin basement membrane syndrome & $19(56 \%)$ & $>0.05$ \\
Secondary FSGS & $30(52 \%)$ & $>0.05$ \\
Other & $33(51 \%)$ & $>0.05$ \\
Minimal change disease & $12(50 \%)$ & $>0.05$ \\
Vasculitis & $34(49 \%)$ & $>0.05$ \\
Lupus nephritis & $7(47 \%)$ & $>0.05$ \\
IgA nephropathy & $32(45 \%)$ & $>0.05$ \\
Acute interstitial nephritis & $12(44 \%)$ & $>0.05$ \\
Cast nephropathy & $6(43 \%)$ & $>0.05$ \\
Nephrosclerosis & $6(43 \%)$ & $>0.05$ \\
Membranous GN & $23(42 \%)$ & $>0.05$ \\
Mild arteriosclerosis & $12(41 \%)$ & $>0.05$ \\
Rapidly progressive GN & $11(41 \%)$ & $>0.05$ \\
Moderate/severe arteriosclerosis & $66(40 \%)$ & $>0.05$ \\
Diabetic nephropathy & $11(28 \%)$ & $0.03^{*}$ \\
Acute tubular necrosis & $4(25 \%)$ & $>0.05$ \\
\hline
\end{tabular}

A significant association could be verified between the presence of DNP and absence of complications.

* $\mathrm{p}$ value calculated by $\chi^{2}$ test. patients (0.6\%). Both of these patients suffered from vasculitis and RPGN. Infection and death did not occur in our population.

Complication rate was the highest in patients who suffered from thin basement membrane syndrome (table 4). Complications occurred in $55.8 \%$ of these patients. In minimal change disease and secondary focal segmental glomerulosclerosis, complication prevalence was also over $50 \%$. In cases of vasculitis and lupus nephritis, the complication rate was also higher than the average rate of complications. In patients with diabetic nephropathy and acute tubular necrosis, development of complications after biopsy was 28.2 and $25 \%$, respectively. This means a significant negative association $(\mathrm{p}<0.05)$ between the complication rate and diabetic nephropathy.

Appearance of several types of complications also varied according to histological diagnoses. The prevalence of perirenal hematomas was similar to the distribution of all complications (table 5). Hematomas at this location were present at a significantly lower rate in patients with diabetic nephropathy and acute tubular necrosis and showed a higher occurrence in thin basement membrane syndrome $(\mathrm{p}<0.05)$. In the latter disease, intrarenal hemorrhage developed in $15 \%$ of cases. This indicates a significant association of this complication with thin basement membrane syndrome $(\mathrm{p}<0.05)$.

The development of spontaneously closing arteriovenous shunts was significantly higher in patients with 
Table 5. Prevalence of hemorrhagic complications in various histological diagnoses

\begin{tabular}{lrll}
\hline & \multicolumn{2}{c}{ Type of hematoma } \\
\cline { 2 - 4 } & perirenal & $\begin{array}{l}\text { intra- } \\
\text { renal }\end{array}$ & $\begin{array}{l}\text { retroperi- } \\
\text { toneal }\end{array}$ \\
\hline Thin basement membrane syndrome & $17(50)$ & $5(15)^{*}$ & $0(0)$ \\
Minimal change disease & $9(38)$ & $2(8)$ & $1(4)$ \\
Secondary FSGS & $27(47)$ & $2(3)$ & $1(2)$ \\
Vasculitis & $31(45)$ & $0(0)$ & $0(0)$ \\
Lupus nephritis & $6(40)$ & $1(7)$ & $1(7)$ \\
Other & $30(46)$ & $0(0)$ & $0(0)$ \\
Membranous GN & $23(43)$ & $1(2)$ & $0(0)$ \\
IgA nephropathy & $29(41)$ & $3(4)$ & $0(0)$ \\
Nephrosclerosis & $6(43)$ & $0(0)$ & $0(0)$ \\
Cast nephropathy & $6(43)$ & $0(0)$ & $1(7)$ \\
Mild arteriosclerosis & $12(41)$ & $2(7)$ & $0(0)$ \\
Moderate/severe arteriosclerosis & $60(37)$ & $3(2)$ & $2(1)$ \\
Acute interstitial nephritis & $9(33)$ & $0(0)$ & $0(0)$ \\
Rapidly progressive GN & $10(37)$ & $0(0)$ & $0(0)$ \\
Diabetic nephropathy & $9(23)^{*}$ & $2(5)$ & $1(3)$ \\
Acute tubular necrosis & $2(13)^{*}$ & $0(0)$ & $0(0)$ \\
\hline
\end{tabular}

There was a significant negative association between the presence of diabetic nephropathy and acute kidney injury and the development of perirenal hematomas, while the presence of thin basement membrane in the biopsy sample showed a positive association with the occurrence of intrarenal hemorrhage.

${ }^{*} \mathrm{p}<0.05$, calculated by $\chi^{2}$ test or Fisher's exact test, as appropriate. Figures in parentheses indicate percentages.

acute interstitial nephritis, RPGN and vasculitis (table 6, $\mathrm{p}<0.05)$. In these diagnoses, the occurrence of shunts was 22,22 and $19 \%$, respectively, while in cases of thin basement membrane syndrome, diabetic nephropathy, nephrosclerosis, arteriosclerosis of different severity, minimal change disease and IgA nephropathy, the presence of arteriovenous shunts was lower than $10 \%$.

Major complications occurred in 10 patients $(2.8 \%$ of all cases). Two patients ( $0.6 \%$ ) required blood transfusion after biopsy; both of them suffered from IgA nephropathy and moderate arteriosclerosis. In 6 cases, selective embolization was needed to treat post-biopsy arteriovenous shunts. Half of these patients had more than one diagnosis. After biopsy, nephrectomy had to be carried out in 2 patients suffering from vasculitis and RPGN, due to large amount of bleeding.

Analyzing clinical parameters, we examined the connection of gender, age, BMI, creatinine levels and hypertension in the patient's history with the complication rate. We did not find significant relationship between creati-
Table 6. Percentage of arteriovenous shunts requiring and not requiring selective embolization in cases of various histological diagnoses

\begin{tabular}{lll}
\hline & $\begin{array}{l}\text { AV shunt } \\
\text { not requiring } \\
\text { selective } \\
\text { embolization }\end{array}$ & $\begin{array}{l}\text { AV shunt } \\
\text { requiring } \\
\text { selective } \\
\text { embolization }\end{array}$ \\
\hline Vasculitis & $13(19 \%)^{*}$ & $2(3 \%)$ \\
Moderate/severe arteriosclerosis & $9(6 \%)$ & $2(1 \%)$ \\
Other & $7(11 \%)$ & $0(0 \%)$ \\
Acute interstitial nephritis & $6(22 \%)^{*}$ & $2(7 \%)$ \\
Rapidly progressive GN & $6(22 \%)^{*}$ & $0(0 \%)$ \\
Secondary FSGS & $4(7 \%)$ & $0(0 \%)$ \\
Thin basement membrane syndrome & $3(9 \%)$ & $0(0 \%)$ \\
Membranous GN & $3(4 \%)$ & $0(0 \%)$ \\
Minimal change disease & $3(13 \%)$ & $1(4 \%)$ \\
Mild arteriosclerosis & $2(7 \%)$ & $0(0 \%)$ \\
Cast nephropathy & $2(14 \%)$ & $0(0 \%)$ \\
Lupus nephritis & $2(13 \%)$ & $0(0 \%)$ \\
Acute tubular necrosis & $2(13 \%)$ & $1(6 \%)$ \\
Diabetic nephropathy & $1(3 \%)$ & $2(5 \%)$ \\
Nephrosclerosis & $0(0 \%)$ & $1(7 \%)$ \\
IgA nephropathy & $0(0 \%)$ & $1(1 \%)$ \\
\hline
\end{tabular}

The presence of spontaneously closing arteriovenous (AV) shunts was significantly associated with acute interstitial nephritis or vasculitis.

${ }^{*} \mathrm{p}<0.05$, calculated by $\chi^{2}$ test or Fisher's exact test, as appropriate.

nine levels or gender and the complication prevalence, but age and BMI showed a significant connection with the development of complications (fig. 3). We found that regardless of histological diagnoses, below the age of 40 years the overall complication rate was $58.3 \%$, in contrast to the percentage of 39.3 detected in patients whose age was over 40 years $(\mathrm{p}<0.05)$. Patients with BMI less than 30 also presented a significantly higher rate of complications than those who had BMI over $30(\mathrm{p}<0.05)$. Presence of hypertension, regardless of its duration, was also associated with a higher rate of perirenal hematomas ( $\mathrm{p}<$ 0.05 , data not shown).

Since the majority of patients had more than one diagnosis and these can interact with each other, we performed logistic regression analysis to cancel out confounders and analyze the effects of diagnoses on complication occurrence separately. With this analysis, we found that the risk for development of any complication after percutaneous renal biopsy in patients with diabetic nephropathy or acute tubular necrosis is 0.44 - and 0.38 - 


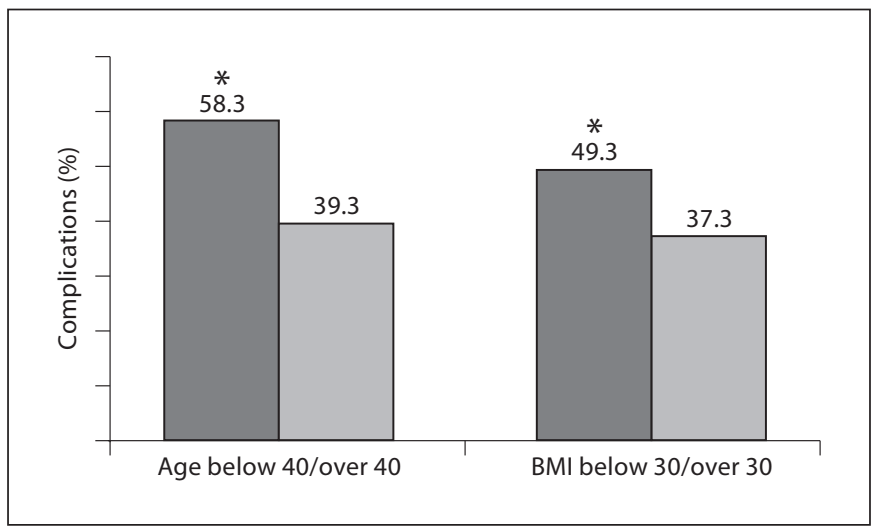

Fig. 3. Effect of age and BMI on complications. Regardless of histological diagnoses, in patients below the age of 40 years the overall complication rate was significantly higher than in patients older than 40 years. Patients with BMI less than 30 also presented a significantly higher rate of complications than those who had BMI over 30 . ${ }^{*} \mathrm{p}<0.05$, calculated by $\chi^{2}$ test.

fold lower than in patients suffering from other kidney diseases, respectively (table 7). In the presence of any of these two diagnoses, the risk for perirenal hematoma is 0.39 - and 0.19 -fold lower, respectively. In contrast, in the case of thin basement membrane syndrome, the chance for intrarenal hemorrhage is 6.67-fold higher after biopsy. The risk for developing an arteriovenous shunt is 3.18 fold higher in acute interstitial nephritis, 2.88 -fold in vasculitis and 0.46 -fold lower in moderate and severe arterio- and arteriolosclerosis.

\section{Discussion}

The aim of this study was to evaluate the connection between the occurrence of various types of complications after percutaneous renal biopsy and the histological diagnoses found in the biopsy tissue. We also analyzed the prevalence of different diseases diagnosed by biopsy in 353 cases.

In our population, the distribution of most diseases in the biopsy specimen was similar to those described by previous papers $[5,6,18-20]$. However, the prevalence of thin basement membrane syndrome was more frequent in our population compared to some studies [7,21]. This is presumably due to the fact that the prevalence of this diagnosis is strongly dependent on the frequency of electron microscopic evaluation, which is carried out in our Department in $100 \%$ of biopsies.
Table 7. Influence of various histological diagnoses on complication occurrence

\begin{tabular}{|c|c|c|}
\hline Complication & Histological diagnosis & LR \\
\hline All complications & $\begin{array}{l}\text { Diabetic nephropathy } \\
\text { Acute tubular necrosis }\end{array}$ & $\begin{array}{l}0.44 \\
0.38\end{array}$ \\
\hline $\begin{array}{l}\text { Perirenal } \\
\text { hematoma }\end{array}$ & $\begin{array}{l}\text { Diabetic nephropathy } \\
\text { Acute tubular necrosis }\end{array}$ & $\begin{array}{l}0.39 \\
0.19\end{array}$ \\
\hline $\begin{array}{l}\text { Intrarenal } \\
\text { hemorrhage }\end{array}$ & $\begin{array}{l}\text { Thin basement membrane } \\
\text { syndrome }\end{array}$ & 6.67 \\
\hline $\begin{array}{l}\text { AV shunt without } \\
\text { embolization }\end{array}$ & $\begin{array}{l}\text { Acute interstitial nephritis } \\
\text { Vasculitis } \\
\text { Moderate and severe arterio- } \\
\text { and arteriolosclerosis }\end{array}$ & $\begin{array}{l}3.18 \\
2.88 \\
0.46\end{array}$ \\
\hline
\end{tabular}

LR $<1$ indicates a negative association between presence of a histological diagnosis and presence of a complication, while LR $>1$ indicates a positive association (logistic regression, $\mathrm{p}<0.05$ ).
Perirenal hematoma can be present in as many as $65 \%$ of patients [22], depending on the post-biopsy control examinations. In our study, complications occurred in $44.5 \%$ of cases. This frequency is similar to that described in previous studies where similar post-biopsy monitoring was performed [2, 10,23]. In contrast, in surveys that did not perform post-biopsy ultrasound examinations routinely, established complication rate was appreciably lower $[7,16,24]$. The most frequent complications were different types of bleedings ( $41.9 \%$ of all patients), mainly perirenal hematomas.

We found that in patients with the diagnosis of diabetic nephropathy or acute tubular necrosis, the overall complication prevalence is significantly lower compared to others. Presumably, this is due to the appreciably lower rate of perirenal hematomas, which represent the majority $(78.6 \%)$ of all complications after biopsy. These results have not been reported previously. The exact reason for these findings is yet unknown. In the case of diabetic nephropathy, the low number of bleeding complications may arise from the accumulation of connective tissue in the kidneys and the developing fibrosis in the vessels as well $[25,26]$. The highest frequency of perirenal hemorrhage as well as a significantly higher rate of intrarenal hemorrhage were present in thin basement membrane syndrome. The risk for intrarenal hematoma was more than 6 -fold higher in patients suffering from this disease. The cause of this phenomenon has also not yet been elucidated, but it may result from the defective collagen 
structures found in the renal tissues of these patients [27], which might cause the spreading of bleeding at the site of puncture.

Patients with moderate and severe arterio- and arteriolosclerosis have a 0.46 -fold risk for developing a postbiopsy arteriovenous shunt compared to others. We do not know the explanation for this interesting phenomenon; further investigations are needed to elucidate its exact reason. In contrast, there is a more than 2 -fold higher risk in patients who have acute interstitial nephritis, vasculitis or RPGN. These associations have been yet unknown. Based on these results, we conclude that diseases where the vessel wall is damaged and vessels are more vulnerable may mean a higher risk for developing arteriovenous shunts. Altogether, ten major complications occurred in our survey, which corresponds with other studies [24, 28]. There were 2 cases where transfusion was required as a consequence of significant decrease in hemoglobin and hematocrit levels. However, hemoglobin levels of these patients were at the lower border of normal range prior to biopsy as well. In 2 patients, nephrectomy had to be performed due to large amount of bleeding which was presumably due to the previously damaged kidneys from vasculitis and RPGN.

Investigating the connection between clinical parameters and complication occurrence, we found that in patients below the age of 40 years complication prevalence is significantly higher than in patients older than 40 years. This may be due to the fact that diseases (i.e. vasculitis and thin basement membrane syndrome) that are associated with higher complication rate are diagnosed mainly at younger age. This finding is in accordance with the results of Stratta et al. [3], while Eiro et al. [10] dem- onstrated contradictory data. According to our survey, a connection between BMI and complication rate also exists. Complication occurrence is significantly higher in patients with BMI below 30 than in others. A possible explanation for this association is the higher frequency of patients with diabetic nephropathy in the group with BMI over 30. As shown earlier, these patients have a significantly lower complication rate.

A possible limitation of our study is the fact that these results are from a single center with a relatively homogenous group of patients, while at the same time this may be an advantage since punctures, ultrasound examinations and evaluations of the samples were performed by the same nephrologists, radiologists and pathologist. Another limitation may be that centers where a preliminary diagnosis cannot be established within the first few hours after biopsy cannot identify patients with a higher risk for complications. For this reason, we emphasize the importance of an early histological diagnosis; however, highrisk patients may already be suspected from their clinical presentation (e.g. patients with acute kidney injury or glomerular hematuria).

Our main finding is that a close relationship exists between certain histological diagnoses and several types of complications which have not been reported yet. We are the first to report that in the presence of diabetic nephropathy or acute tubular necrosis the risk for post-biopsy bleeding is significantly lower compared to others, and we also describe for the first time that in vasculitis, RPGN, thin basement membrane syndrome or acute interstitial nephritis, the risk for various complications is higher than in other patients. In the patients with a higher risk, stricter post-biopsy monitoring may be necessary.

\section{References}

1 Whittier WL, Korbet SM: Renal biopsy: update. Curr Opin Nephrol Hypertens 2004;13: 661-665.

-2 Manno C, Strippoli GF, Arnesano L, Bonifati C, Campobasso N, Gesualdo L, Schena FP: Predictors of bleeding complications in percutaneous ultrasound-guided renal biopsy. Kidney Int 2004;66:1570-1577.

-3 Stratta P, Canavese C, Marengo M, Mesiano P, Besso L, Quaglia M, Bergamo D, Monga G, Mazzucco G, Ciccone G: Risk management of renal biopsy: 1387 cases over 30 years in a single centre. Eur J Clin Invest 2007;37:954963.
-4 Hergesell O, Felten H, Andrassy K: Safety of ultrasound-guided percutaneous renal biopsy-retrospective analysis of 1090 consecutive cases. Nephrol Dial Transplant 1998;13:975977.

5 Rychlík I, Jancová E, Tesar V, Kolsky A, Lácha J, Stejskal J, Stejskalová A, Dusek J, Herout V: The Czech registry of renal biopsies. Occurrence of renal diseases in the years 1994-2000. Nephrol Dial Transplant 2004; 19:3040-3049.

-6 Gesualdo L, Di Palma AM, Morrone LF Strippoli GF, Schena FP, Italian Immunopathology Group, Italian Society of Nephrology: The Italian experience of the national registry of renal biopsies. Kidney Int 2004; 66:890-894.
7 Toledo K, Pérez MJ, Espinosa M, Gómez J, López M, Redondo D, Ortega R, Aljama P: Complications associated with percutaneous renal biopsy in Spain, 50 years later. Nefrologia 2010;30:539-543.

-8 Ishikawa E, Nomura S, Hamaguchi T, Obe T, Inoue-Kiyohara M, Oosugi K, Katayama K, Ito $\mathrm{M}$ : Ultrasonography as a predictor of overt bleeding after renal biopsy. Clin Exp Nephrol 2009;13:325-331.

-9 Waldo B, Korbet SM, Freimanis MG, Lewis EJ: The value of post-biopsy ultrasound in predicting complications after percutaneous renal biopsy of native kidneys. Nephrol Dial Transplant 2009;24:2433-2439. 
-10 Eiro M, Katoh T, Watanabe T: Risk factors for bleeding complications in percutaneous renal biopsy. Clin Exp Nephrol 2005;9:4045.

-11 Soares SM, Fervenza FC, Lager DJ, Gertz MA, Cosio FG, Leung N: Bleeding complications after transcutaneous kidney biopsy in patients with systemic amyloidosis: singlecenter experience in 101 patients. Am J Kidney Dis 2008;52:1079-1083.

12 Walker PD, Cavallo T, Bonsib SM: Practice guidelines for the renal biopsy. Mod Pathol 2004; 17:1555-1563.

-13 Darouich S, Goucha RL, Jaafoura MH, Moussa FB, Zekri S, Maiz HB: Value of electron microscopy in the diagnosis of glomerular diseases. Ultrastruct Pathol 2010;34:49.

14 Racusen LC, Solez K, Colvin RB, et al: The Banff 97 working classification of renal allograft pathology. Kidney Int 1999;55:713723.

15 Bader H, Meyer DS: The size of the juxtaglomerular apparatus in diabetic glomerulosclerosis and its correlation with arteriolosclerosis and arterial hypertension: a morphometric light microscopic study on human renal biopsies. Clin Nephrol 1977;8:308-311.

16 Whittier WL, Korbet SM: Timing of complications in percutaneous renal biopsy. J Am Soc Nephrol 2004; 15:142-147.
17 Bollée G, Martinez F, Moulin B, Meulders Q, Rougier JP, Baumelou A, Glotz D, Subra JF, Ulinski T, Vrigneaud L, Brasseur J, Martin L, Daniel L, Kourilsky O, Deteix P, Sie P, Ronco P, Houillier P: Renal biopsy practice in France: results of a nationwide study. Nephrol Dial Transplant 2010;25:35793585.

18 Sipiczki T, Ondrik Z, Abrahám G, Pokorny G, Túri S, Sonkodi S, Kemény E, Iványi B: The incidence of renal diseases as diagnosed by biopsy in Hungary. Orv Hetil 2004;145: 1373-1379.

19 Rivera F, López-Gómez JM, Pérez-García R: Frequency of renal pathology in Spain 19941999. Nephrol Dial Transplant 2002;17: 1594-1602.

20 Briganti EM, Dowling J, Finlay M, Hill PA, Jones CL, Kincaid-Smith PS, Sinclair R, McNeil JJ, Atkins RC: The incidence of biopsyproven glomerulonephritis in Australia. Nephrol Dial Transplant 2001;16:1364-1367.

21 Schena FP: Survey of the Italian Registry of Renal Biopsies. Frequency of the renal diseases for 7 consecutive years. Nephrol Dial Transplant 1997;12:418-426.

22 Walker PD: The renal biopsy. Arch Pathol Lab Med 2009;133:181-188.

23 Castoldi MC, Del Moro RM, D’Urbano ML, Ferrario F, Porri MT, Maldifassi P, D’Amico G, Casolo F: Sonography after renal biopsy: assessment of its role in 230 consecutive cas es. Abdom Imaging 1994;19:72-77.
24 Nyman RS, Cappelen-Smith J, al Suhaibani $\mathrm{H}$, Alfurayh O, Shakweer W, Akhtar M: Yield and complications in percutaneous renal biopsy. A comparison between ultrasound guided gun-biopsy and manual techniques in native and transplant kidneys. Acta Radiol 1997;38:431-436.

25 Kim Y, Kleppel MM, Butkowski R, Mauer SM, Wieslander J, Michael AF: Differential expression of basement membrane collagen chains in diabetic nephropathy. Am J Pathol 1991;138:413-420.

26 Ban CR, Twigg SM: Fibrosis in diabetes complications: pathogenic mechanisms and circulating and urinary markers. Vasc Health Risk Manag 2008;4:575-596.

-27 Frascà GM, Onetti-Muda A, Mari F, Longo I, Scala E, Pescucci C, Roccatello D, Alpa M, Coppo R, Li Volti G, Feriozzi S, Bergesio F, Schena FP, Renieri A, Italian Renal Immunopathology Group: Thin glomerular basement membrane disease: clinical significance of a morphological diagnosis - a collaborative study of the Italian Renal Immunopathology Group. Nephrol Dial Transplant 2005;20:545-551.

28 Christensen J, Lindequist S, Knudsen DU, Pedersen RS: Ultrasound-guided renal biopsy with biopsy gun technique - efficacy and complications. Acta Radiol 1995;36:276279. 